\title{
UPAYA MENINGKATKAN KARAKTER MANDIRI SISWA TK B PUSPA MELATI JEMBER MELALUI MEDIA PERMAINAN RAKYAT ENGKLEK
}

\author{
${ }^{1}$ Lutfiatul Munawaroh, ${ }^{2}$ Arifin Nur Budiono, ${ }^{3}$ Fakhruddin Mutakin \\ ${ }^{1}$ Mahasiswa Prodi Bimbingan dan Konseling, FKIP, Universitas Islam Jember, Indonesia \\ ${ }^{2}$ Dosen Prodi Bimbingan dan Konseling, FKIP, Universitas Islam Jember, Indonesia \\ ${ }^{3}$ Dosen Prodi Bimbingan dan Konseling, FKIP, Universitas Islam Jember, Indonesia \\ Email : aghif.fatih@gmail.com, budiononur05@gmail.com, fakhrudcounseling@gmail.com
}

\begin{abstract}
ABSTRAK
Pendidikan karakter adalah sebuah usaha mendidik anak-anak agar dapat mengambil keputusan dan mempraktekannya dalam kehidupan sehari-hari. Peneliti melakukan observasi di TK B Puspa Melati Jember semester ganjil tahun pelajaran 2019-2020 dan diperoleh data sekitar 46\% atau hampir setengah dari peserta didikyang ada mengalami tingkat kemandirian diri rendah. Penelitian ini bertujuan untuk meningkatkan karakter mandiri melalui permainan rakyat engklek.jenis penelitian yang digunakan adalah penelitian tindakan kelas (PTK). Prosedur yang digunakan adalah model siklus. Berdasarkan hasil penelitian, siklus I siswa masih belum menunjukkan sikap mandiri. Siklus II siswa sudah berkembang sesuai harapan (BSH), bahkan ada beberapa yang berkembang sangat baik (BSB). Hal tersebut dapat disimpulkan bahwa permainan rakyat engklek dapat meningkatkan karakter mandiri siswa.
\end{abstract}

Kata Kunci :Karakter Mandiri, Permainan Rakyat Engklek

\begin{abstract}
ABSRTACT
Character education is an effort to educate children in order to make decisions and practice them in their daily lives. Researchers are observing at TK B Puspa Melati Jember Odd semester year lesson 2019-2020 and obtained data about $46 \%$ or nearly half of the existing learners experiencing a level of low self-reliance. This research aims to improve the character's self-reliant through the game people's crank. The type of research used is research into class action (PTK). The procedure used is a cycle model. Based on the research results, the I cycle of students still has no independent attitude. Cycle II students have developed as expected (BSH), there are even some that are developing very well (BSB). It can be concluded that the people's games can improve the students ' independent character.
\end{abstract}

Keywords: Independent Characters, the People's Game Crank 


\section{PENDAHULUAN}

Karakter bangsa merupakan hal yang sangat esensial dalam kehidupan bermasyarakat, berbangsa dan bernegara. Karakter akan senantiasa menjadi roh dan kekuatan bangsa untuk menghadapi setiap perkembangan, termasuk tantangan dunia global. Oleh karena itu, pendidikan karakter harus diperjuangkan sekuat tenaga. Terlebih lagi dengan Kurikulum 2013 yang mengedepankan pendidikan budi pekerti diharapkan membentuk insan yang cerdas dan berkarakter. Hasil observasi di TK B Puspa Melati Jember di peroleh data bahwa siswa TK B Puspa Melati Jember memiliki tingkat kemandirian diri rendah. Hal ini dapat dilihat dari sikap para siswa yang masih belum terbiasa untuk tidak bergantung pada orang lain, terbiasa mengambil keputusan secara mandiri, terbiasah menyelesaikan, merencanakan, memilih, dan memiliki inisiatif untuk belajar atau melakukan sesuatu tanpa harus dibantu orang lain.Hasil analisis yang dilakuakan saat observasi awal, masalah-masalah tersebut terjadi karena kurangnya media dalam meningkatkan karakter mandiri, maka dengan itu solusi yang diberikan oleh peneliti untuk meningkatkan dan memperkuat karakter mandiri siswa melalui kinestetik yaitu dengan memberikan media yang mengasikkan dan tidak membosankan salah satunya dengan belajar sambil bermain dengan permainan tradisional engklek.

Ratna Megawangi (2007:104 ) juga mengemukakan "Pendidikan karakter adalah sebuah usaha mendidik anak-anak agar dapat mengambil keputusan dan mempraktekannya dalam kehidupan sehari-hari, sehingga anak-anak dapat memberikan konstribusi yang positif pada lingkungannya". Anak usia dini merupakan masa yang tepat untuk menanamkan pendidikan karakter, sebab pada masa ini anak sedang mengalami fase pertumbuhan dan perkembangan yang luar biasa, selain itu anak juga belum memiliki pengaruh negatif yang banyak dari luar atau lingkungannya sehingga orang tua ataupun pendidik akan lebih mudah dalam mengarahkan memimbing anak maupun anak didiknya, terutama dalam menanamkan dan pembinaan nilainilai pendidikan karakter. Pendidikan karakter bagi anak usia dini adalah untuk menanamkan nilai-nilai kebaikan supaya menjadi kebiasaan kelak ketika dewasa atau pada jenjang pendidikan selanjutnya.

Suparman (2003: 31) meyimpulkan bahwa pendidikan karakter mandiri adalah pendidikan yang membentuk akhlak, watak, budi pekerti, dan mental manusia agar hidupnya tidak tergantung atau bersandar kepada pihak-pihak lain, tidak bergantung pada bantuan orang lain.

Pendidikan karakter mandiri bertujuan untuk insan-insan yang percaya kepada dirinya sendiri dalam mengerjakan sesuatu urusan. Karakter mandiri mendorong dan memacu seseorang untuk memecahkan sendiri persoalan hidup dan kehidupannya, sehingga dia termotivasi untuk berinisiatif, berkreasi, berinovasi, proaktif dan bekerja keras. Pendidikan budi pekerti mandiri memacu keberanian seseorang untuk berbuat atau bereaksi, tidak pasrah dan beku, tetap dinamis, energik dan selalu optimis menuju ke masa depan.

Berdasarkan uraian tentang karakter di atas, kegiatan pendidikan harus sesuai dan memberikan warna pada 
setiap tahap dari tiga domain, yakni akal, hati dan amal. Untuk membentuk karakter mandiri siswa, sebenarnya diperlukan pelajaran khusus yang berkenaan dengan pembentukan karakter mandiri, seperti kewirausahaan, sistem nilai kemandirian, dan sebagainya, namun mengingat jam belajar siswa disekolah sudah cukup padat, maka alternatif yang dapat diambil adalah dengan mengintegrasikan materi pembelajaran yang ada dengan memunculkan muatan-muatan pembentuk karakter mandiri siswa. Berkaitan dengan sekuensial tiga domain di atas, maka untuk membangun karakter mandiri diperlukan tiga teknik yang merupakan suatu kesatuan. Teknik tersebut antara lain: 1). Proses Pembentukan Akal Kemandirian, 2). Proses Pembentukan Hati Kemandirian, 3). Proses Pembentukan Amal Kemandirian.

Istilah 'Engklek' berasal dari bahasa Jawa, di daerah Riau disebut Setatak, di daerah Jambi disebut Tejektejekan, sedangkan di daerah Batak Toba dikenal Marsitekka. Pendapat Rahmawati (2009: 10) menyatakan bahwa engklek atau sondah adalah permainan meloncati garis dengan satu kaki, permainan ini di daerah Jawa Barat dan dari luar Jawa. Sedangkan menurut Dharmamulya (2008: 145) Permainan ini dinamakan juga engklek atau ingkling. Dinamakan demikian karena dilakukan dengan melakukan engklek, yaitu berjalan melompat dengan satu kaki. Pendapat lain dipaparkan oleh Mulyati (2013: 46) bahwa dinamakan engklek karena bermainnya menggunakan satu kaki yang dalam bahasa jawa artinya 'engklek'.

Dari uraian diatas dapat disimpulkan bahwa permainan engklek adalah permainan yang menggunakan medialgambar persegi empat yang digambar di lantai ataupun di tanah yang cara memainkannya dengan cara melompati garis dengan satu kaki. Permainan engklek mempunyai banyak jenis dan ragamnya.

Engklek merupakan salah satu dari sekian banyak permainan tradisional yang mengandung sportifitas, kebersamaan, kerja keras, dan kesenangan. Oleh karena itu, sudah menjadi pilihan bagaimana seharusnya engklek menjadi permainan yang dipertahankan.

Engklek menurut Winaya (2014) dalam artikelnya yang berjudul "Pengertian Sikan-Mesikatau Engklek" adalah suatu permainan tradisional lompat-lompatan pada bidang datar yang telah diberi garis pola kotak-kotak, kemudian melompat dengan satu kaki dari kotak satu ke kotak berikutnya. Muncul pula pendapat bahwa permainan tradisional engklek mempunyai nama asli "Zondag Maandag" yang merupakan bahasa Belanda. Jadi berdasarkan sejarahnya memang permainan tradisional engklek ini masuk ke Indonesia pada waktu Belanda menjajah Indonesia.

Engklek bertujuan untuk menjadi penyeimbang di tengah maraknya permainan modern. Di dalam permainan modern lebih cenderung mengembangkan otak kiri, otak kanan, dan kreativitas. Di dalam permainan tradisional lebih dari itu, yaitu melatih empati, mengenal dirinya dan alam. Dengan mengenal diri dan alam, dia mengenal Tuhannya. Selain itu permainan engklek juga dimaksudkan untuk mengangkat nilainya, bukan hanya artefaknya. Nilai-nilai yang terkandung dalam permainan engklek yang relevan 
dengan konsep kekinian. Jadi begitu nilainya diangkat, orang-orang akan menerima itu. Nilai-nilai yang terkandung dalam permainan engklek bisa dilihat dari berbagai macam, ada nilai perkembangan fisik, nilai untuk kesehatan mental, nilai sosial, dan problem solving.

Engklek sebagai permainan tradisional diharapkan dapat digunakan sebagai sarana pembelajaran, seperti telah diungkapkan, bahwa engklek mengandung nilai-nilai budi pekerti yang bermanfaat bagi siswa. Siswa tidak selalu belajar didalam kelas, namun sesekali mereka dibiarkan belajar sambil bermain di luar kelas. Mengapa engklek penting sebagai sarana pendidikan, dolanan engklek memuat empat kecerdasan bagi anak, yaitu kecerdasan kinestetik, kecerdasan intrapersonal, kecerdasan interpersonal, dan kecerdasan naturalis.

\section{METODE}

Penelitian yang digunkan adalah menggunakan media permainan rakyat engklek.

\section{a. Langkah-langkah engklek \\ bermain}

1. Semua pemain melakukan hom pimpa yang menang berhak melakukan permaian terlebih dahulu.

2. Pemain pertama melemparkan gaco (yang biasanya berupa pecahan genting/kreweng, keramik lantai, ataupun batu yang datar) ke kotak nomor satu. Saat melemparkannya tidak boleh melebihi kotak yang telah disediakan jika melebihi maka dinyatakan gugur.

3. Pemain Pertama melompat dengan satu kaki (Engklek), dari kotak 1 sampai kotak 8 kemudian berhenti sejenak di kotak A kemudian kembali lagi dengan mengambil gaco yang ada di kotak satu dengan posisi kaki satu masih diangkat.

4. Setelah itu pemain melemparkan gaco tersebut sampai ke kotak 2 jika keluar dari kotak 2 maka pemain dinyatakan gugur dan diganti oleh pemain berikutnya. Begitu seterusnya sampai semua kotak sudah dilempar dengan gaco.

5. Pergiliran dilakukan jika pemain pelempar gaco melewati sasaran, atau menampak dua kaki dikotak $1,2,3,4,5,6$ dan berhenti sejenak di kotak A kemudian lompat lagi di kotak 3 dan berhenti di kotak 2 untuk mengambil gaco di kotak 1 .

6. Jika gaco berada dikotak 2 maka pemain mengambilnya di kotak 3 , jika gaco berada di kotak 4, 5 dan 6 maka pemain mengambilnya di kotak $A$.

7. Kemudian jika semua telah dilakukan oleh semua pemain maka pemain melemparkan gaco dengan membelakangi engkleknya jika pas pada kotak yang dikehendaki maka kotak itu akan menjadi rumahnya maka boleh berhenti dikotak tersebut seperti pada kotak A tapi hanya berlaku pada pemain yang menang pada permaian tersebut. Begitu seterusnya sampai kotak-kotak mulai dari angka 1 sampai 6 menjadi milik para pemain.

8. Jika semua telah dimiliki oleh sang pemain maka permainan dinyatakan telah selesai. Pemenang adalah pemain yang paling banyak memiliki rumah dari kotak-kotak pada Engklek yang digambar.

\section{b. Tehnik Penelitian}


1. JenisPpenelitian

Jenis penelitian yang digunakan adalah penelitian tindakan kelas

2. Pendekatan Penelitian

Dalam penelitian ini menggunakan pendekatan kualitatif

Dalam pelaksanaan Penelitian Tindakan Kelas (PTK) ini melalui dua tahapan siklus yang akan dilakukan oleh peneliti untuk meningkatkan kemandirian siswa TK Puspa Melati melalui media permainan rakyat engklek. Siklus pertama maupun siklus kedua tahapan-tahapannya sama, secara umum, PTK dilaksanakan dalam bentuk siklus berulang-ulang, empat bagian utama yang ada dalam setiap siklus adalah sebagai berikut: perencanaan, pelaksanaan, pengamatan, refleksi. Indikator keberhasilan dari penelitian ini apabila setengah atau $50 \%$ dari responden mampu meningkatkan kemandiriannya pada tahap berkembang sesuai dengan harapan (BSH).

Populasi pada penelitian ini adalah siswa TK Puspa Melati Jember Tahun Ajaran 2019-2020. Sampel pada penelitian ini adalah siswa TK B Puspa Melati Jember, yang mempunyai tingkat kemandirian diri rendah.

\section{Rubrik/ Penilaian Observasi}

\begin{tabular}{ll}
\hline Kategori & \multicolumn{1}{c}{ Keterangan } \\
\hline BB (Belum Berkembang) & $\begin{array}{l}\text { Pencapaian perkembangan yang diharapkan masih harus } \\
\text { mendapatkan bimbingan, dicontohkan dan dimotivasi. }\end{array}$ \\
MB (Mulai Berkembang) & $\begin{array}{l}\text { Pencapaian perkembangan yang diharapkan sudah mulai } \\
\text { berkembang namun masih perlu diingatkan. }\end{array}$ \\
BSH (Berkembang & $\begin{array}{l}\text { Pencapaian perkembangan yang diharapkan sudah mulai } \\
\text { dilakukan dengan baik, benar, cepat dan tepat. }\end{array}$ \\
BSB (Berkembang & Pencapaian perkembangan yang diharapkan sudah sangat \\
Sangat Baik) & baik dengan respon yang cepat, tepat dan benar, selain itu \\
& anak juga dapat mengingatkan orang lain.
\end{tabular}

Sumber : Modul P4TK dan PLB bandung 2017.

Dalam penelitian ini analisis data yang digunakan adalah analisis data dari Miles \& Huberman yang terdiri dari tiga tahapan :

\section{Reduksi Data}

Reduksi data adalah merekam atau mengambil data-data yang ada di lapangan dalam bentuk catatan-catatan lapangan, di tafsirkan atau diseleksi yang sesuai denga fokus masalah yang diteliti.

Penyediaan Data atau Display Data
Display data adalah menyajikan data dalam bentuk matriks, chart atau grafik, network dan sebagainya

\section{Mengambil Kesimpulan Data atau Verifikasi}

Kesimpulan data berupa hasil dari keseluruhan kegiatan observasi dan hasil catatan lapangan yang dianalisis berupa diskripsi dalam bentuk penarikan kesimpulan. Data dari hasil evaluasi dan kesimpulan observasi dianalisis berupa kompilasi data dengan rubrik penilaian 
yang merujuk pada modul P4TK TK dan PLB Bandung.

\section{HASIL DAN PEMBAHASAN}

Berdasarkan penelitian yang bersumber dari hasil wawancara, observasi dan dokumentasi yang dilakukan saat kegiatan belajar mengajar yang ada di sekolah TK Puspa Melati Jember tahun ajaran 20192020 terhadap penerapan media permainan engklek maka diperoleh data berupa perkembangan prilaku siswa yang menunjukkan pada katagori berkembang sesuai dengan harapan (BSH) bahkan ada beberapa yang berkembang sangat baik (BSB). Secara umum persentase anak pada siklus I masih belum memenuhi indikator keberhasilan dalam penelitian ini, berdasarkan kekurangan pada siklus I, guru membuat perencanaan yang lebih menarik pada siklus II, hal ini dilakukan agar anak dapat lebih semangat dan tidak bosan dalam bermain permainan engklek. Guru mengajak anak untuk bermain dengan dilombakan antar siswa .Hal ini dapat membangunkan semangat anak dan membuatnya semakin greget dalam bermain, dilihat anak lebih senang, komperatif, antusias dan bersemangat, sehingga penilaian kemampuan anak dapat memenuhi indikator keberhasilan. Siswa mengalami peningkatan karena siswa sangat senang dan suka bermain permainan engklek, sehingga dengan melakukan permainan ini akan melatih siswa menjadi lebih berani, mau berkerja keras/berusaha, selain itu siswa jugamulai berani mau mengungkapkan pendapatnya saat kegiatan recalling, yang mana hal tersebut merupakan salah satu prilaku yang mencerminkan karakter mandiri.
Pada siklus I terjadi peningkatan prilaku mandiri dengan 9 siswa yang menunjukan prilaku mandirinya pada tahap MB, dan 4 siswa lagi pada tahap $\mathrm{BSH}$. Sedangkan peningkatan pada siklus II dengan 6 siswa pada tahap BSB, 6 siswa pada tahap $\mathrm{BSH}$, dan 1 siswa yang masih pada tahap MB. Dari hasil siklus II ini dapat diketahui adanya peningkatan yang sangat baik, walaupun masih ada anak yang pada tahap MB, namun lebih banyak siswa yang menunjukkan peningkatan pada tahap BSH bahkan ada beberapa anak BSB pada prilaku mandirinya. Berdasarkan hasil penelitian proses tindakan bermain engklek diketahui bahwa tingkat karakter mandiri siswa meningkat pada setiap siklus penelitian, sehingga dapat dikatakan bahwa penerapan tindakan dengan media permainan engklek pada penelitian ini mampu membantu meningkatkan karakter mandiri siswa TK B Puspa Melati Jember.

\section{SIMPULAN}

Berdasarkan penelitian yang dilakukan dari analisis data dan pengujian hipotesis, maka dapat diambil kesimpulan bahwa peningkatan karakter mandiri siswa ini dibuktikan dengan adanya perubahan prilaku siswa yang awalnya tingkat kemandiriannya belum berkembang setelah diberikan tindakan permainan engklek ini, kemandirian siswa berkembang sesuai dengan harapan bahkan ada beberapa yang berkembang sangat baik. Oleh karena itu, hipotesis yang telah dibuat oleh peneliti sudah bisa diketahui yaitu penerapan permainan engklek dapat meningkatkan karakter mandiri siswa TK B Puspa Melati Jember semester ganjil tahun ajaran 2019/2020. 


\section{DAFTAR PUSTAKA}

Arikunto. 2010. Prosedur Penelitian Suatu

Tindakan Praktik. Jakarta : PT Rineka Cipta

Budiono, Arifin Nur. 2019 Buku Pedoman Penyusunan Proposal dan Skripsi. Pustaka Radja

Dharmamulya, Sukirman. dkk. 2008. Permainan Tradisional Jawa. Yogyakarta: kepel Press. MuhammadiyahSurakarta.

Iskandar. 2012, penelitian tindakan kelas. Jakarta Selatan: Refrensi (GP Press Group)

Kurniati, E. 2011. Program Bimbingan untuk Mengembangkan

Keterampilan Sosial Anak Melalui Permainan Tradisional.Surakarta: Skripsi Universitas

Megawangi, Ratna. 2004. Pendidikan Karakter. Jakarta: Indonesia Heritage Foundation.

Rahmawati, Ami.2009. Permainan Tradisional Untuk Anak Usia 4-3 Tahun. Bandung.Sandiarta Sukses.

Rahmawati, Rudy Budiman 2017. Modul Pembinaan Karir Guru Melalui Peningkatan Kopetensi Terintregasi Penguatan Pendidikan Karakter Bidang TK. P4TK dan PLB Bandung.

Winaya. 2014. Pengertian Sikan-Mesikatau Engklek : Engklek Sebagai Sarana Pembelajaran Yang AsikDi Tengah Permainan Modern. Progdi Pendidikan Bahasa Jawa, FKIP Universitas Widya Dharma Klaten

http// psikologi.fisip-unmul.ac.id 